\title{
Agnieszka Mierzwińska-Hajnos
}

Maria Curie-Skłodowska University, Pl. M. C. Skłodowskiej 5, 20-031 Lublin, Poland

\section{More than Blends and Compounds. Conceptual Integration Theory behind Plant-Related Linguistic Expressions in Polish and English}

\begin{abstract}
The present paper offers a semantic analysis of selected plant-related Polish and English blends and compounds in the light of Conceptual Integration Theory (cf. Fauconnier and Turner 1998, 2002). As defined by Fauconnier and Turner, conceptual integration is a dynamic process which allows us to account for novel expressions that emerge as the result of complex mental operations during which various elements of disparate domains might be activated and entrenched in a given context. Therefore, plant-related blends and compounds such as nagietek, lemonata, or kora dębowa will be put here under scrutiny and analysed with the aid of the four-space network model.

Keywords: Conceptual Integration Theory, cognitive semantics, conceptual blends, dynamicity
\end{abstract}

\section{Introduction}

The dynamic and ubiquitous character of the cognitive mental operation known as conceptual blending can hardly be overlooked once its mechanisms operate within a plethora of linguistic instances such as neologisms, or novel expressions. This paper focuses on the phenomenon of conceptual integration hidden behind plant-related 
expressions as, for instance, Polish nagietek (Eng. "marigold"), and English lemonata or bananular, where, to successfully decode their meanings, the knowledge from various domains must be combined and activated (cf. Coulson 2001). This happens by virtue of the socalled meaning construction, the process whereby language "prompts for novel cognitive representations of varying degrees of complexity" (Evans and Green 2006: 363). Being viewed as a fundamentally conceptual phenomenon, meaning construction should first and foremost be analyzed "with reference to the conceptualizations that give rise to it" (Hampe 2000: 85), as well as take into account two other basic parameters, i.e. on-line dynamic process and contextdependent interpretation. In this respect, the aspect of meaning construction and its countless interpretive possibilities lead us towards a great mental capacity known as conceptual blending - an operation that is "vital to creative thinking and consists in mapping, exploration and transformation of structures and conceptual spaces" (Del Bello 2007: 161). Assuming that the whole process of conceptualization is based upon complex conceptual processing where language is but a factor that helps to encode the actual meaning ${ }^{1}$, it seems justifiable to reach for such tools as Conceptual Blending Theory and apply it to the struggle over semantic analysis of plant-related lexical blends and compounds.

\footnotetext{
An interesting observation on that issue is made by Turner (1993: 206):

Expressions do not mean; they are prompts for us to construct meanings by working with processes we already know. In no sense is the meaning of [an]... utterance "right there in the words". When we understand an utterance, we in no sense are understanding "just what the words say"; the words themselves say nothing independent of the richly detailed knowledge and powerful cognitive processes we bring to bear.
} 


\section{More than Blends and Compounds. Conceptual Integration Theory}

2. Conceptual Blending Theory: general assumptions

Conceptual Blending Theory (henceforth: CBT), also known as Conceptual Integration Theory, is one of the most novel trends that have emerged in the cognitive paradigm in recent years and still occupies a privileged position in the field of cognitive semantics. ${ }^{2}$ The theory, first proposed by Gilles Fauconnier and Mark Turner (cf. Fauconnier and Turner 1998, 2002), and further developed by other contemporary linguists (cf. Coulson 2001, Coulson and Oakley 2000, Oakley and Coulson 2008, Libura 2007, 2010, Brandt and Brandt 2005, Brandt 2005, Brandt 2013), is successfully applied in various branches of contemporary linguistics (i.a. Kemmer 2003, Joy et al. 2009, Delibegović Džanić 2007, Omazić 2005).

In terms of its architecture and central fundamentals relative to the dynamic aspects of meaning construction, Conceptual Blending Theory is often considered to be a development of Mental Spaces Theory (Fauconnier 1994). One cannot, however, deny the fact that Conceptual Blending Theory should rather be viewed as an approach deriving from two major traditions within cognitive semantics, i.e. Mental Spaces Theory and Conceptual Metaphor Theory ${ }^{3}$ (cf. Evans

\footnotetext{
2 It has to be noted that Conceptual Blending Theory (CBT) does not exclusively refer to linguistics but can also be successfully adopted in a wide range of other scientific disciplines, such as literary studies, cognitive psychology, anthropology, computer sciences, religious studies, arts, or mathematics. Fauconnier and Turner emphasize the ubiquitous function of CTB in the following statement (2002: vi, see also Libura 2007):

We argue that conceptual blending underlies and makes possible all these diverse human accomplishments, that it is responsible for the origins of language, art, religion, science, and other singular human feats, and that it is as indispensable for basic everyday thought as it is for artistic and scientific abilities

Veale and O'Donoghue perceive CBT as the continuation of research upon metaphor (2000: 253):

[The] many space or conceptual integration network theory of Fauconnier an Turner $(1994 ; 1998)$ is an elaboration of the two-space model of metaphor that has been the cornerstone of the metaphor field since Aristotle (see Hutton 1982), and which has underpinned a string of conceptual theories from Richards (1936), through Black (1962), and Koestler (1964) to Lakoff and Johnson (1980).
} 
\& Green 2006: 400), and operate whenever any of the above theories fails to account for linguistic phenomena.

Assuming that conceptual integration is "a basic cognitive operation that operates uniformly at different levels of abstraction and under superficially divergent contextual circumstances" (Fauconnier and Turner 2006: 304), Fauconnier and Turner propose a basic integration network which allows us to establish the emergent meaning, successfully linking elements from Mental Spaces Theory and Conceptual Metaphor Theory. In the proposed model, mental spaces, described as "small conceptual packets construed as we think and talk, for local understanding and action" (Fauconnier and Turner 2002: 40), are linked on the basis of the so-called partial cross-space mapping that connects respective counterparts in the input spaces. Since the integration network is not a two-space entity, but aims to account for a dynamic aspect of meaning construction, the so-called generic space containing shared characteristics of the input spaces must be activated. These three spaces link with the fourth space called the blended space or "the blend" that, apart from containing generic structure captured in the generic space, displays the structure not available in the inputs. A basic diagram of an integration network as proposed by Fauconnier and Turner is presented in Figure 1:

Other linguists, e.g. Grady, Oakley and Coulson (1999) emphasize the importance of Conceptual Metaphor Theory (CMT) as the factor that allows viewing CBT and CMT as complementary rather than competitive. 


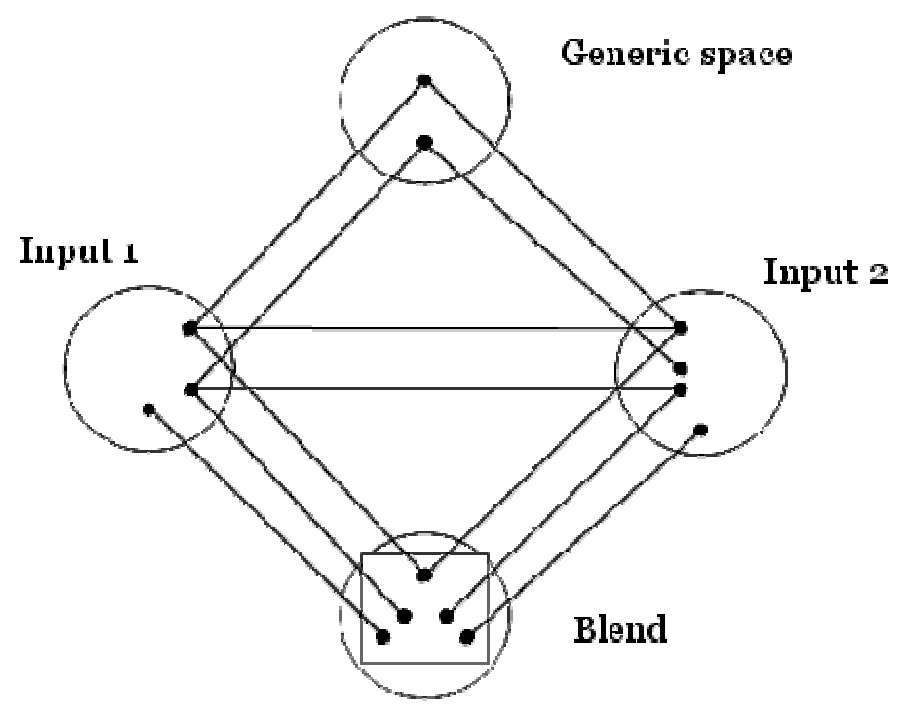

Figure 1. The basic four-space integration network (after Fauconnier and Turner 2002: 46).

Particular attention should be drawn to the blended space which is responsible for developing the so-called emergent structure. The emergent structure, considered CBT's outstanding achievement, posits that a blend, constructed from the selected input space elements, acquires an additional element - a part of meaning which does not come from the meaning of input space elements. Hence, the blend becomes a novel meaning of new quality that derives from neither of the inputs. The emergent structure enables us to comprehend the overall meaning of a blend, which cannot be inferred from the blend components. Additionally, a thorough comprehension is also possible owing to a "background frame" (Evans and Green 2006: 409) containing the additional real-world knowledge, automatically evoked the moment we encounter a blend. 
The aforementioned emergent structure arises as the result of three component processes: (i) composition; (ii) completion; and (iii) elaboration. Composition structures elements from the inputs, allowing for the selective projection of necessary information that is indispensable "for purposes of local understanding" (cf. Evans and Green 2006: 409). The value obtained in the blended space does not carry the characteristics observed in the input spaces. Still, being perceived as a salient part of blending, it frequently requires completion by "unconscious and effortless recruitment of background frames" (cf. Evans and Green 2006: 409). This is completion, indispensable to derive the blend. The final stage, known as elaboration or running the blend, is an on-line process that allows the establishment of a dynamic scenario for the emergent structure integrated in the blend, simultaneously allowing for composition and completion processes. ${ }^{4}$

A good illustration accounting for all the processes activated during conceptual integration is the instance of lexical blend appleanche. To fully observe the aforementioned stages participating in the process of shaping the emergent structure in the blend, consider Figure 2:

\footnotetext{
4 Ungerer notices that "elaboration may be envisaged as a test of the correctness and consistency of the conceptual content of the blended space" (2007: 656).
} 


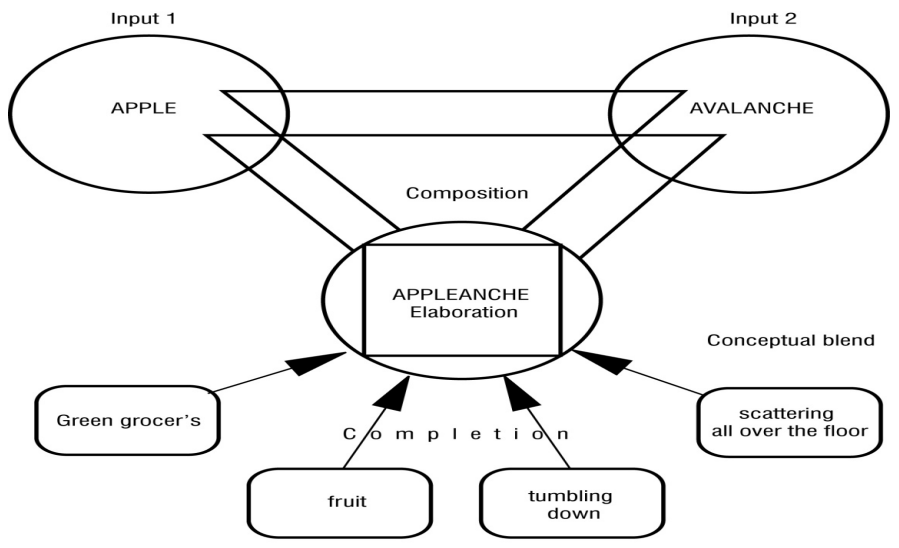

Figure 2. Composition, completion and elaboration processes in conceptual integration (based on Fauconnier's concept of wheelchair, Fauconnier 1997: 151).

In order to account for the emergent meaning that arises in the blend, we are forced to recall the context which enables to run the blend successfully. Let us consider the following sentence: "Ashley gently pulled the perfect Macintosh from the middle of the grocery display when suddenly everything shifted and there was a loud rumble. "Run for your lives", she exclaimed, "APPLEANCHE!" „(source: www.urbandictionary.com). It can be seen that the emergent meaning appleanche, defined as "a situation in which a grocer's vertical display of fresh fruit, particularly apples, comes tumbling down and scatters across the floor of the store" (source: www.urbandictionary.com), is not the result of "mutual adhesion of simple words" (Jakobson 1965:32), but rather the result of conceptual fusion which indicates what is happening between two disparate concepts: [APPLE] and [AVALANCHE]. Both these concepts contribute to the projection from the two inputs onto the blended space in the mechanism of composition. In addition, background knowledge (represented here by such notions as grocer's, fruit, floor, 
tumbling down, or scattering all over the floor), viewed as completion, is activated in order to help us account for the meaning. Finally, appleanche receives its meaning potential via elaboration - a dynamic on-line process which allows us to activate our thoughts and obtain a particular usage according to the required context.

Although the notion of blending as well as three component processes are of vital importance to properly construct and decode a conceptual blend, on no account should we ignore other mechanisms of conceptual integration that stand behind the scene. They have to be recalled whenever we are to account for the meaning via CBT. One of these mechanisms are the so-called constitutive principles (cf. Fauconnier and Turner 2002; also Libura 2007). ${ }^{5}$ However, the effective and creative character of blends does not depend solely on those principles. The understanding and interpretation of new meanings that arise in the blended space is also the result of "making sense of many disparate events and experiences" (Evans and Green 2006: 419). To achieve this, the notion of compression of vital relations such as change, identity, time, space, cause-effect, partwhole, representation, role-value, analogy, disanalogy, property, similarity, category, intentionality, or uniqueness has to be brought to existence. This element also allows us to assess the character of blend and understand its creativity. ${ }^{6}$

Another important aspect that has to be taken into account while discussing CBT concerns the organisation of integration networks. Multiple possibilities pointing to the division of mental spaces involved in the blending process, the connections among them,

\footnotetext{
5 The authors of The Way We Think enumerate the following constitutive principles indispensable in the process of conceptual blending: 1. matching counterpart connections 2 . generic space 3 . blending 4 . selective projection 5 . emergent meaning 6. composition 7. completion 8. elaboration (see Fauconnier and Turner 2002).

6 Since the compression of Vital Relations is described in detail by Fauconnier and Turner, as well as by others (cf. Libura 2007; also Evans \& Green 2006), the author of this paper considers it unnecessary to provide a full theoretical description of those processes, simultaneously stating that selected ones will be taken into consideration while analyzing the data.
} 
various types of projection and emergence, and finally the wealth of possibilities to obtain diversified blends require that a clear division of integration networks should also be brought to existence. According to Fauconnier and Turner, the diversity of integration networks forms a continuum, among which four integration networks, i.e. simplex, mirror, single-scope and double scope, stand out as basic types needed for precise analysis of conceptual blends (Fauconnier and Turner 2002: 119).

Having discussed basic assumptions of Conceptual Integration Theory, the basic network model as delineated by Fauconnier and Turner will now be applied to the analysis of plant-related expressions retrieved from Polish and English. The proposed analysis will concern two linguistic phenomena, i.e. compounds and blends.

\section{Compounds and conceptual blending}

In a vivid discussion upon form and meaning, Fauconnier and Turner emphasize a significant role of Conceptual Blending Theory in the construction of compounds (2002: 353-406). Since human beings are equipped with a cognitive apparatus that enables them to "bring two things together mentally in various ways" (ibid., 353), CBT proves to be a useful tool that allows us to ponder over the aspect of unpredictable and non-compositional nature of certain expressions.

Compounds, though seemingly simple for analysis, remain a hard nut to crack whenever cognitive semantics is taken into account. Being a part of word formation process, they involve a semantic combination, or fusion which permits a conceptual blending analysis. Let us now recall a seemingly simple English compound cherry jeans, thoroughly discussed by Ungerer and Schmid (2006: 271-275). An indepth analysis of the aforementioned example proves that Conceptual Blending Theory touches upon much more complicated processes and is not only a simple and unproblematic analysis that leads towards a unified account of a given blend. On the contrary, it indicates the noncompositional nature of creative compounds, whose integration is 
dynamic and context-dependent. ${ }^{7}$ Consider Ungerer and Schmid's instance of "cherry jeans" (Figure 3):

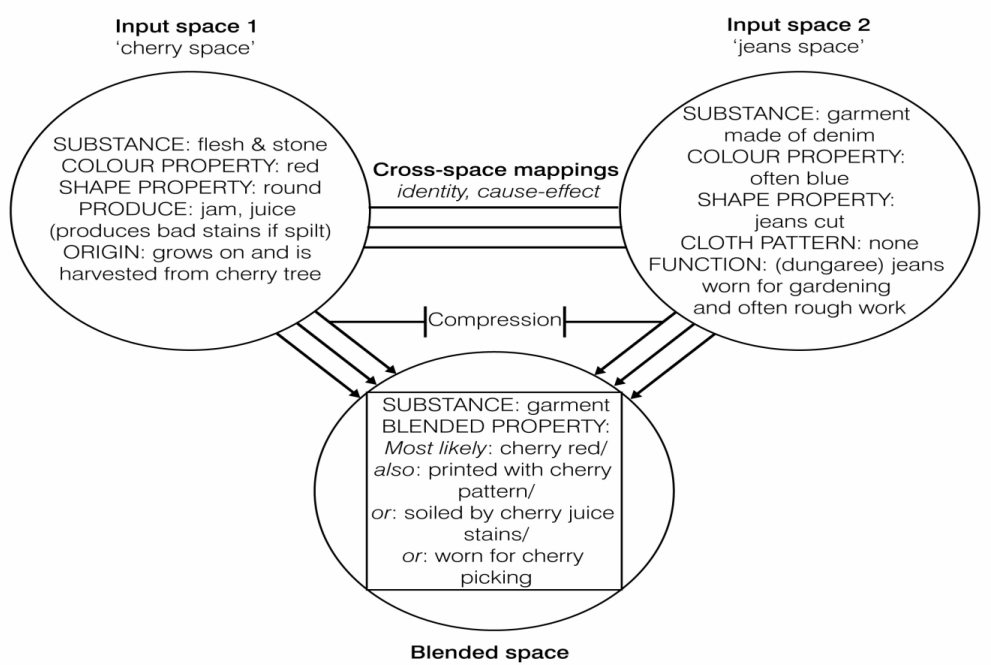

Figure 3. Network representation of the cherry-jeans blend (Ungerer and Schmid 2006: 272)

According to the conventional interpretation of an expression's meaning, cherry-jeans stands for "jeans of cherry-like colour". The entrenched meaning is the result of cross-space mapping which includes the vital relation between the colour property as depicted in Input Space 1 (the cherry space) and the colour property taken from Input Space 2 (the jeans space). The value obtained in the blended space that points to cherry-red colour of jeans is the result of projection and compression of colour properties from both input spaces.

7 It is worth considering the following observation made by Plag (2003:132), "compounding is a field of study where intricate problems abound, numerous issues remain unresolved and convincing solutions are generally not so easy to find". 
Apart from the entrenched meaning of cherry jeans, there are also other ad hoc conceptualizations pointing to different emergent structures that might appear in the blend. Cherry jeans may stand for: (i) "garment soiled by stains of cherry juice" as well as (ii) "jeans used for cherry-picking". In the first case we rely on the completion process which allows us to recall the accident of staining garment with cherry juice. The cause and effect vital relation that establishes a cross-space mapping of cause (the cherry space) an effect (a cherry colour stain on jeans), is finally activated and compressed into the blend as "cherry jeans - garment soiled by stains of cherry juice".

No less interesting is the conceptualization of cherry jeans standing for "jeans used for cherry picking". As in the previous example, a cause-effect relation touches upon the traditional function of jeans (i.e. jeans used for gardening work, cherry picking included), understood here as the cause, and the effect of cherries being harvested (the "origin" element of the cherry space). The background which contributes to the shape of an actual meaning allows for the context of picking cherries involved with climbing cherry trees or dirty ladders and, what follows, using special clothing. The knowledge pointing to a potential "cherry picker" who intends to wear a pair of jeans for this activity is also brought to existence.

The non-compositionality as well as the activation of various scenarios for such compounds as cherry jeans uncover a very important feature of CBT: expressions, being non-compositional, are more likely to reveal their on-line dynamic meaning, according to the recalled context. The above constellations enable us to run the blend dynamically: although cherry jeans conceptualized as (i) "garment soiled by stains of cherry juice" and (ii) "jeans used for cherrypicking" are unlikely to achieve wider prevalence or stability, they do become a typical product of "context-dependent on-line conceptualization" (Ungerer and Schmid 2006: 271).

As it is seen, we have the potential to create many different blends out of the same inputs: using the same processes, we obtain different 
results (Fauconnier and Turner 2002: 26). ${ }^{8}$ This observation in turn refers us to another conclusion- blending process should not be reduced just to "blending" but should rather be viewed as "a component of many diverse constructions" (Fauconnier and Turner 2002: 365).

The cherry-jeans case as proposed by Ungerer and Schmid (2006) is not the only instance where CBT proves to be a reliable source of an expression's analysis. Another interesting instance that meets all the demands of semantic analysis in the light of Fauconnier and Turner's theory is a Polish expression dębowa kora (Eng. lit. „oak bark”, retrieved from Słownik tajemnych gwar przestepczych 1993: 101). Apart from its literal meaning which refers to the outer part of a tree (in this case an oak tree) that overlays the wood, dębowa kora also stands for "prison garment" in prisoners' jargon in Poland. The online meaning that is conveyed in the expression is presented in Figure 4:

\footnotetext{
8 A similar instance is thoroughly discussed by Fauconnier and Tuner (2002: 27): "Red pencil" can be taken to mean a pencil whose wood has been painted red on the outside, a pencil that leaves a red mark (the lead is red, or the chemical in the pencil reacts with the paper to produce red, or...) a pencil used to record the activities of a team dressed in red, a pencil smeared with lipstick, or a pencil used only for recording deficits. Theories of semantics typically prefer to work with examples like "black bird" or "brown cow" since these examples are supposed to be the principal examples of compositionality of meaning, but [...] even these examples illustrate complicated processes of conceptual integration.

We need to make a clear distinction between seemingly identical cases in the Polish language, viz. dębowa kora, discussed above, and kora dębowa- an expression that stands for at least two different concepts: 1 . the literal expression that describes the outermost layer of an oak and 2. the drug containing tannins used in the treatment of inflammatory skin diseases as well as local treatment of mild inflammation of the oral cavity and pharyngeal region.
} 


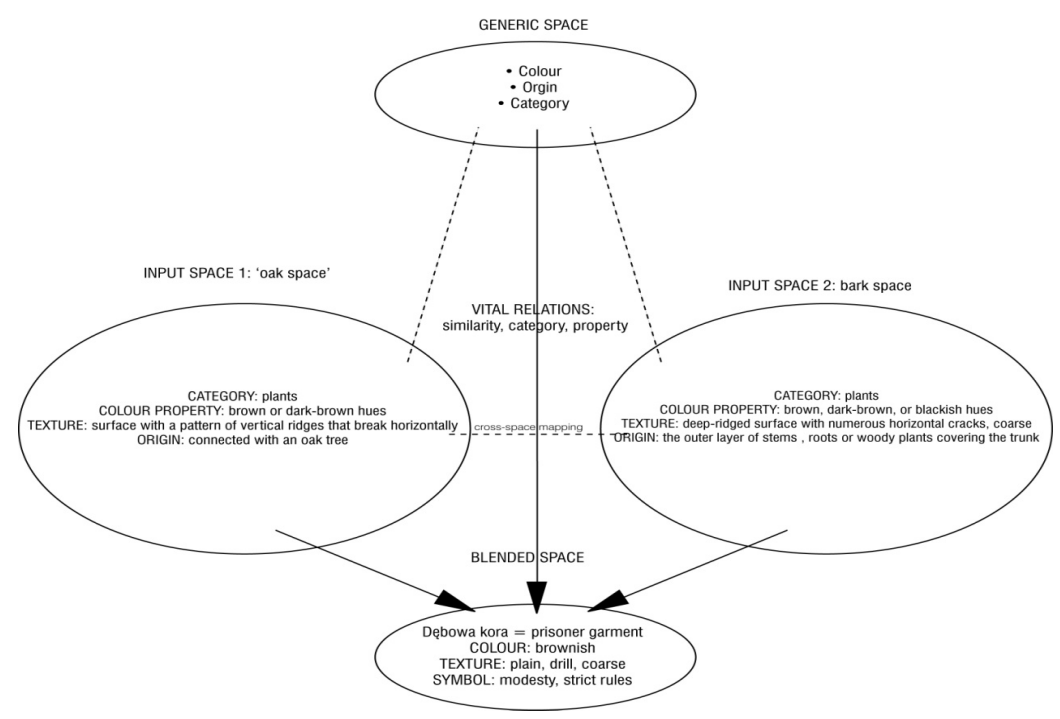

Figure 4. Conceptual integration of dębowa kora "oak bark”.

Input space 1 recalls the concept of an adjective dębowy "oak", input space 2 evokes the characteristics of another concept kora "bark". Selected features of both input spaces, such as, e.g. texture, origin, or colour, are connected by three vital relations: similarity, category and property, indicated by the dotted line of cross-space mapping in the diagram. The emergent structure dębowa kora "oak bark" gains its meaning from both input spaces and the generic space and points to a prison garment - brownish plain drill clothes worn by prisoners in Polish prisons. ${ }^{10}$

As it results from the analyzed examples, Fauconnier and Turner's theory proves extremely successful as far as the so-called

10 An interesting remark pointing to the expression dębowa kora can be found on the symbolic level: not only does the brown colour in the analyzed expression refer to an oak species, but it is also considered as the symbol of modesty or strict rules. (cf. Rejakowa 2008: 137-138). 
"distributed" nature of word-meaning is concerned (Evans and Tyler 2004). Compounds, being "context-sensitive", have the potential to derive from a diverse range of contexts, which undoubtedly allows us to set the scene for such mental operations as conceptual integration.

Nevertheless, there are still skeptical voices, even among cognitivists, whether Fauconnier and Turner's theory should be considered "the golden means" that meets all the demands governing the compounding process. ${ }^{11}$ Whichever option is favoured, one cannot deny the tremendous function CBT plays to unveil the unpredictability and partial compositionality of meaning found in such expressions (cf. Fauconnier and Turner 2002; Kardela 2006).

\section{Lexical vs. conceptual blends}

The most obvious and simultaneously most complicated instances of conceptual blending can be found in the field of a word-formation process known as lexical blending. Lexical blends are generally viewed as instances of "telescoping two words into a new one" (Ungerer and Schmid 2006: 268). Nevertheless, "a new lexeme formed from parts of two or more other lexemes" (Bauer 1988: 238) can also be successfully tackled using Conceptual Blending Theory which, apart from operating on a purely morphological structure, allows for the integration process on the level of semantic pole and phonological pole of each symbolic unit. ${ }^{\mathbf{1 2}}$

11 Bundgaard and Stjernfelt notice (2006: 370): "blending theory on its own merely diagrams the dynamic, cognitive process of meaning construal; it does not describe compounding as a linguistic phenomenon an therefore has only limited descriptive import". Sweetser (1999) also points to limited possibilities of CBT, claiming that the analysis of compounding requires the full "regalia" of cognitive linguistics, including Langacker's notion of construal and profiling (Langacker 1987, 1991, 2000), or Ryder's (1994) linguistic templates which are based on schema theory (after Benczes 2006: 68).

12 It has to be noted that the term blend has a wide application and may successfully indicate a morphological as well as a phonological blend. Both these terms, however popular, do not allow for the conceptual integration as proposed by Fauconnier and Turner in which the blend (or rather the conceptual blend) refers to the amalgamation process on the conceptual level (cf. Kardela 2006). 
Let us take into consideration an English word lemonata, the result of blending process of two source lexemes, [LEMON x dATA ]which appears in the following sentence: "Saddam has weapons of mass destruction", said Bush, relying on convenient "spinata that later turned lemonata". (source: www.urbandictionary.com)

To account for the meaning of lemonata, it is necessary to recall the input space of "lemon", "an oval fruit which has a thick yellow skin and sour juice" and the input space of "data", "information, especially facts, collected to be examined and considered and used to help decision-making". The emergent meaning which is the result of blending two input spaces points to "facts that later turn sour, revealing them to be wishful thinking or flat-out lies". ${ }^{13}$ In the case of George W. Bush, his knowledge about Saddam Hussein having weapon of mass destruction gave the US President a solid argument to start the American invasion of Iraq, the argument which turned out to be only wishful thinking but proved to be convincing enough to gain public consent for the war in Iraq.

Let us now analyze selected English and Polish blends which operate in the same way as previously discussed lemonata: ${ }^{14}$

- meloncholy "a gloomy state of mind, achieved after eating a copious amount of fruit"

[MELON x melanCHOLY]

- bananular "a nice, compact, travel-size type of banana phone" [BANANa x cellULAR]

- lemonlicious "an adjective that describes an edible that is absolutely scrumptious and doesn't necessarily have to taste lemony" [LEMON x deLICIOUS]

13 Interesting analogies can be traced between lemonata and another English expression sour grapes - in both these cases an emphasis is laid upon the inability to achieve the expected result.

14 The data retrieverd from www.urbandictionary.com and Stownik tajemnych gwar przestepczych (1993). 
- broccoflower "a vegetable that is half broccoli and half cauliflower"

[BROCCOli x cauliFLOWER]

- stokrótka "rozwódka" (Eng. "a divorcée")

[STOKRoTka x rozwÓdKA]

nagietek "orgia seksualna" (Eng. "a sexual orgy")

[NAgi x orGIETKa]

The above examples allow to establish certain properties that can be grouped according to various instances of blending. As pointed out by Kemmer (2003:75-76):

1. Blends combine parts of lexical source words, rather than whole source words; this distinguishes them from compounds

2. Morphological structure in not particularly relevant to blends. Source lexemes are combined without regard to their morphological boundaries, and the internal structure of the resultant blend is not necessarily morphologically analyzable concatenatively. It is usual to find morphological overlap, residue, and/or clipped forms, rather than exhaustive divisibility of the blend into sequential, whole morphemes.

3. Phonological properties are highly relevant to blending; phonological similarity of the blend with part or whole source lexemes increases the likelihood of felicity (the "goodness") of a blend. Similarity can range from segmental identity through segmental similarity to same or similar syllable structure; and the similarity can range from identity/similarity of the blend with both source lexemes, to one source lexeme, or to parts of these.

Adopting the spirit of cognitive linguistics, it is mandatory to consider lexical blends as symbolic units which consist of a semantic pole and phonological pole (cf. Langacker 1987: 83-86). As it was proved by Kemmer (2003: 82-83), the process of conceptual integration in the sense of Fauconnier and Turner may be observed on both these poles. ${ }^{15}$ Let us take into account the phonological pole, where the so-

15 Consider the following statement made by Langacker (2008: 105):

The symbolic structure is not distinct from semantic or phonological structure. Symbolic units are "bipolar": they consist of a semantic unit, at one pole, in symbolic association with a phonological unit, at the other. 
called phonological connections are shared by both source lexemes and the blend. As it is emphasized by Kemmer, "a phonological string (...) might contain a syllable as well as segmental material of different degrees of specificity" (2003: 81). Take meloncholy for instance. Although not as conspicuous as Kemmer's swooshstika, the blend displays a schematic phonological representation where alternate consonants and vowels form the following array: bilabial nasal (indicated by M) - vowel (V) - lateral approximant (L) - reduced vowel (v) - alveolar nasal $(\mathrm{N})$. It is obvious that the phonological representation $\left[\mathrm{mel}^{\mathrm{D}} \mathrm{n}\right]$ is shared by three forms: two source lexemes, melon and melancholy, and the blend meloncholy. The phonological overlap as observed in meloncholy allows an average user to trace the phonological connection, which, according to Kemmer, "makes blends (...) especially felicitous and appreciated by speakers for their activity". (2003: 81). To obtain a fuller picture of phonological relations, consider Figure 5:

Assuming that each lexical unit is a symbolic unit where the integration process operates both on the phonological pole and the semantic pole, Kemmer (2003) analyzed two instances pointing to the problem: swooshstika to illustrate the integration within a phonological pole and the glitterati case which depicts the integration on the semantic pole. 


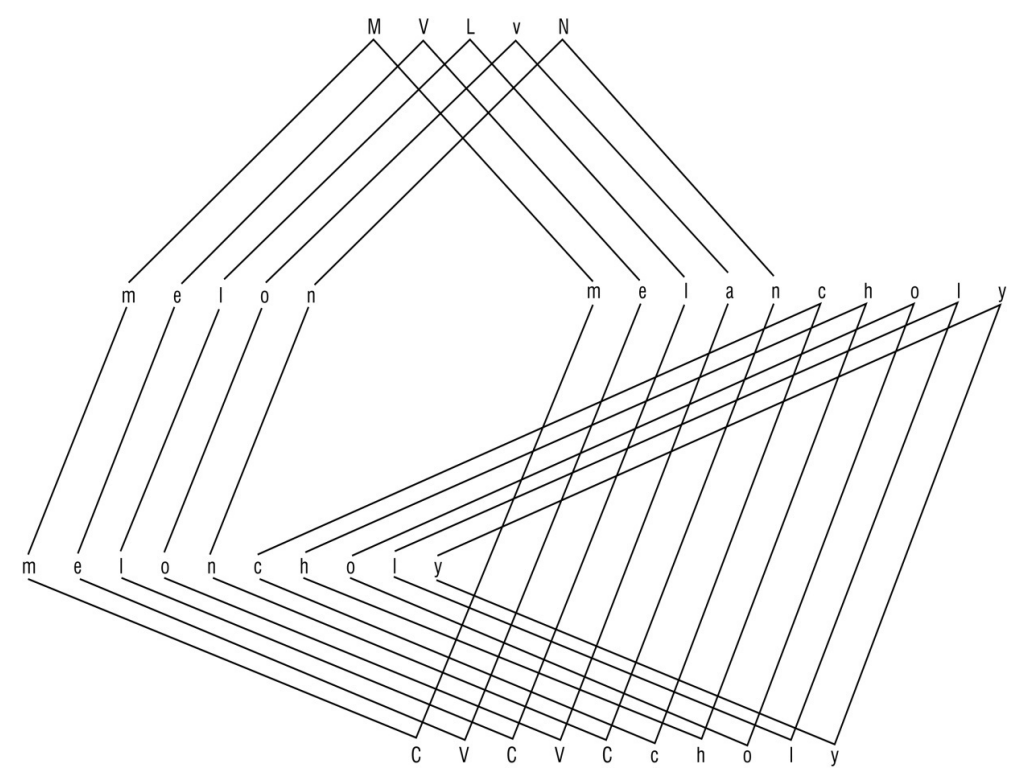

Figure 5. Phonological relations in an English blend meloncholy (based on Kemmer 2003: 82).

Let us now consider how the process of blending the operates on the semantic pole. To deal with this phenomenon, we need to recall another interesting example, a vegeterrorist, the blend that is the result of conceptual integration of two input spaces: vegetarian and terrorist. Figure 6 depicts the amalgamation process of two input spaces that occurs on the semantic pole: 


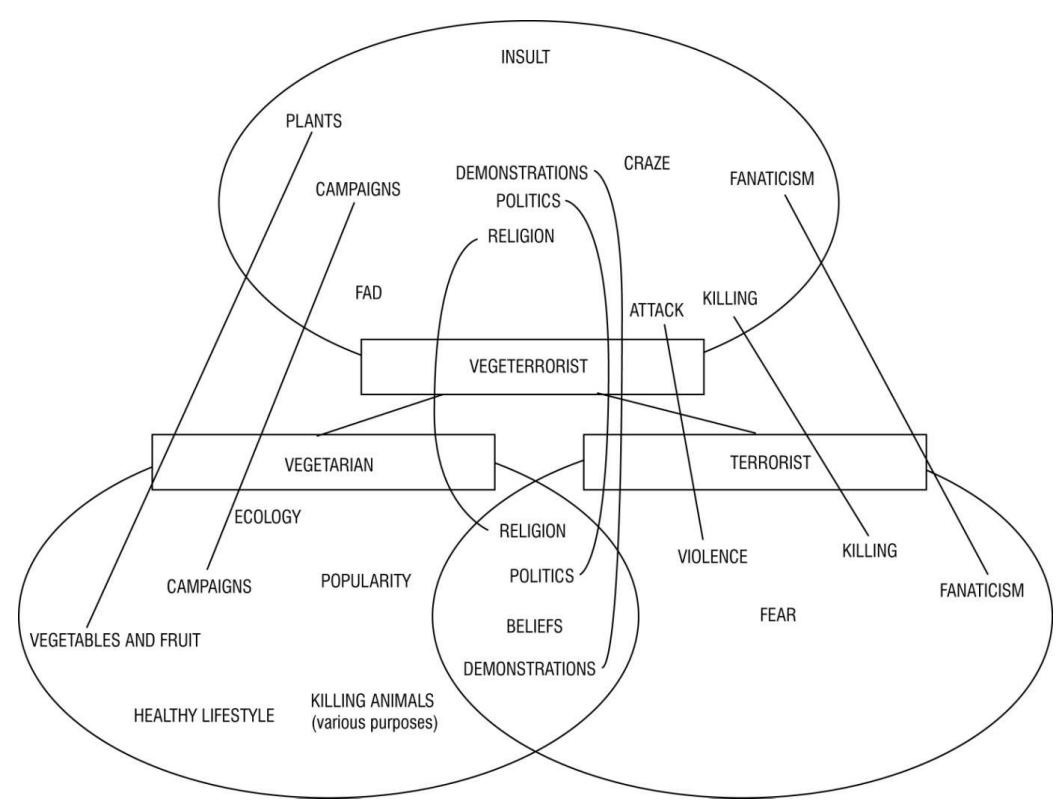

Figure 6. The semantic pole of vegeterrorist (based on Kemmer 2003: 84).

As it is seen in the diagram, the emergent meaning of vegeterrorist, "a vegetarian that plans, participates or organizes demonstrations or attacks against people or places that eat or otherwise use animal products" (source: www.urbandictionary.com), is the result of semantic overlap of elements derived from two input spaces. Input space 1 concerns vegetarians - people who do not eat meat for health or religious reasons or because they do not want to do any harm to animals. The space also triggers off associations pointing to ecology, being en vogue, an finally taking a radical attitude against killing animals for various purposes such as eating or otherwise, in campaigns and demonstrations. Input space 2 recalls the image of a terrorist, a person who uses violent action for political purposes, usually at demonstrations and causes fear. The value obtained in the blended space draws selected elements, such as "vegetables and fruit", 
"religion", "fanaticism", "demonstrations and campaigns" from both input spaces, simultaneously comprising those elements that cannot be traced in any of the input spaces, e.g. "insult", "attack", "craze" or "fad". 16

The phenomenon of blending, with overlapping phonological and semantic elements from input spaces should not be discussed only with reference to single lexical items. Kemmer notices that many concepts that are "interpretable out of context" (2003: 87) are liable to rely on the exact form and meaning displayed by one element. Thus, a dynamic change of a concept is built up upon one element of the blend that provides unchangeable properties, and the constant change that is brought together with another element of the analyzed blend. ${ }^{17}$ Consider the expression potato-gate that appeared as the element of the following newspaper headline: Potato-Gate. Poland's government feels snubbed by Germany. (source: www.atlantic-times.com). The unchangeable element -gate stands for the notion of "a scandal" that took place after having labelled the Kaczyński brothers potatoes. Running the blend dynamically consists in attaching various elements to a constant element of -gate, which, depending on the context, stands for "a scandal", or any other "illegal manoeuvres in politics, among politicians or celebrities". Thus, the common ground of -gate becomes a basis for other blends which carry various associations (cf. the potato-gate and instances given by Kemmer, such as Watergate,

16 All these elements link successfully with the idea of vegeterrorist who, despite shared characteristics, can be identified with the person who sets attacks on people eating meat or wearing leather shoes or fur coats, insults or undermines the opinion of such people, especially celebrities, or finally becomes a "fanatic" who is actively involved in the whole process of fighting against non-vegetarians because such an attitude is popular, although it might be considered only a fad or craze that lasts for a very short time.

17 Kemmer makes the following observation on that issue (2003: 91):

probably the most common type of blend generating (...) word families is the substitution blend, in which one source lexeme replaces part of the other. This replacement brings to bear a new conceptual domain in the blend, which then selects aspects of each domain to highlight in the coherent overall conceptualization. 
Contragate, travelgate, Monicagate, Camillagate or Notting Hillgate (2003: 91)).

Both Kemmer's thorough analysis as well as instances referring to plant names and plant-related terminology discussed in this paper allow to view Fauconnier and Turner's theory as the one that successfully recalls many levels of reflection and research (cf. Oakley \& Hougaard 2008). Even discussing such narrow branches of linguistics as lexical blends, it is possible to recall the guidelines of the conceptual integration theory. This is what makes Fauconnier and Turner's approach a flexible method of interpretation in many fields of contemporary linguistics.

5. Concluding remarks

The present paper tackles an important aspect of semantic analysis of selected plant-related Polish and English blends and compounds in the light of conceptual integration theory as proposed by Gilles Fauconnier and Mark Turner (Fauconnier and Turner 1998, 2002). Assuming that "conceptual blending is often argued to be a fundamental cognitive operation that is central to general properties of human thought and imagination" (Evans and Green 2006: 439), one cannot question the ubiquity and importance of conceptual blends in language. Plant-related morphological blends and compounds discussed above indicate that the Fauconnier and Turner's approach proves to be a particularly successful tool in an attempt to understand novel expressions, whenever the information from different domains has to be integrated. What is more, the network model delineated by Fauconnier and Turner allows us to grasp metaphor-related phenomena more fully and enables subtle analysis of various novel expressions, thus contributing to the description of certain conceptual phenomena "with greater systematicity than [it] was available before" (Kövecses 2002: 237).

The main aim of this study is to depict enormous potential of lexical meaning hidden behind Polish and English common plant names and plant-related expressions, with the aid of Fauconnier and 
Turner's theory. As observed by Riemer (2005: 2, emphasis mine, $\mathrm{AMH}$,

In its identification of meaning and mental structure, cognitive grammar has broadened the scope of linguistic research, giving proper recognition to a host of phenomena which had to be ignored under earlier, more austere conceptions of language. (...) One of the most salutary achievements of cognitive linguistics has been to restore to the appreciation of language the phenomenon of meaningfulness in all its multifaceted indeterminacy. (...) The emphasis from the start of the cognitive linguistic tradition on imagery, metaphor, and figurative language has revealed multiple dependencies between linguistic expressions and other aspects of cognition, dependencies which now form an inalienable part of our knowledge of the wider psychological context of linguistic facts, and which will have to be accounted for somehow in any definitive theory of language.

The proposed analysis focuses on plant-related compounds and morphological blends. It seems that in case of morphological blends, the process of conceptual blending is even more conspicuous and dynamic in comparison to compounds, since it captures both the semantic and phonological pole immediately as indispensable components of a symbolic unit compressed in a one-word concept (cf. Langacker 1987). In case of the analyzed compounds, a conceptual integration via the semantic pole prevails, the phonological pole being neglected while arriving at the emergent meaning. Nevertheless, both compounds and morphological blends indicate relatively rapid changes in language, frequently reaching for old formulae couched in an innovative way. Hence, such neologisms as the examined bananular, lemonata, nagietek, kora dębowa that gain the status of novel expressions while activating and integrating disparate concepts occurring in input spaces.

Obviously, the paper does not fully exploit the potential of Fauconnier and Turner's theory, but strives to pose, rather than give answers to, numerous questions that might occur while accounting for a linguistic meaning. A conceptual blend, hidden behind a linguistic expression might also be shaped by other spaces activated, spaces that are not present the classical conceptual network model proposed by Fauconnier and Turner. Therefore, it seems advisable to refer to revised models of conceptual integration, as those proposed, e.g. by 
Brandt and Brandt (2005), or Oakley and Coulson (2008), to indicate other parameters indispensable in decoding the emergent meaning of each conceptual blend.

\section{References}

Bauer, L. 1988. Introducing linguistic morphology. Edinburgh: Edinburgh University Press.

Benczes, R. 2006. Creative compounding in English: the semantics of metaphorical and metonymical noun-noun combinations. Amsterdam/Philadelphia: John Benjamins Publishing Company.

Black, M. 1962. Models and metaphors. Ithaca: Cornell University Press.

Brandt, L. \& Brandt, P. A. 2005. Making sense of a blend. A cognitive-semiotic approach to metaphor. In: Ruiz de Mendoza Ibáñez, F. J. (ed.) Annual Review of Cognitive Linguistics 3. Amsterdam,/Philadelphia: John Benjamins Publishing Company. 216-249.

Brandt, P. A. 2005. Mental spaces and cognitive semantics: a critical comment. In Journal of Pragmatics 37.1578-1594.

Brandt, L. 2013. The Communicative Mind: A Linguistic Exploration of Conceptual Integration and Meaning Construction. Newcastle upon Tyne: Cambridge Scholars Publishing.

Bundgaard, P. and F. Stjernfelt. 2006. Waterproof Fire Stations : Conceptual schemata and cognitive operations involved in compound constructions. In: Semiotica 161. 363-393.

Bybee, J. 1985. Morphology. A Study in the Relation between Meaning and Form. Amsterdam/ Philadelphia: John Benjamins.

Coulson, S. 2001. Semantic leaps: frame-shifting and conceptual blending in meaning construction. New York: Cambridge University Press.

Coulson, S., Oakley, T. (eds.) 2000. Special Issue on Conceptual Blending. In: Cognitive Linguistics, 11, 3/4. 175-360.

Del Bello, D. 2007. Forgotten Paths: Etymology and Allegorical Mindset. Washington, D.C. Catholic University of America Press.

Delibegović Džanić, N. 2007. Conceptual Integration Theory - the Key for Unlocking the Internal Cognitive Choreography of Idiom. In: Linguistics (Jezikoslovlije) 8 (2). 169-191.

Evans, V. and A. Tyler. 2004. Spatial experience, lexical structure and motivation: the case of ,in”. In: Radden, G. and K. U. Panther (eds.) Studies in Linguistic Motivation. Berlin: Mouton de Gruyter. 157-192. 
Evans, V. and M. Green. 2006. Cognitive Linguistics: An Introduction. Edinburgh: Edinburgh University Press.

Fauconnier G. 1994 [1985]. Mental Spaces, $2^{\text {nd }}$ ed. Cambridge: CUP.

Fauconnier G. 1997. Mappings in Thought and Language. Cambridge: CUP.

Fauconnier, G. and M. Turner. 1996. Blending as a central process of grammar. In: A.Goldberg (ed.) Conceptual Structure, Discourse and Language. Stanford, California: Center for the Study of Language and Information Publications. 113130.

Fauconnier, G. and M. Turner. 1998. Conceptual Integration Networks. In: Cognitive Science 22 (2). 133-187.

Fauconnier, G. and M. Turner. 2002. The Way We Think: Conceptual Blending and the Mind"s Hidden Complexities. New York: Basic Books.

Fauconnier, G. and M. Turner. 2006. Mental Spaces. Conceptual Integration Networks. In: Geeraerts, D. (ed.), Cognitive Linguistics. Basic Readings. Walter de Gruyter.303-371.

Geeraerts, D. and H. Cuyckens (eds). 2007. The Oxford Handbook of Cognitive Linguistics. Oxford: OUP.

Grady, J., Oakley, T., Coulson, S. 1999. Blending and Metaphor. In: Gibbs, R. And Steen, G. (eds.) Metaphor in Cognitive Linguistics. Amsterdam: John Benjamins. 79- 100 .

Hampe, B. 2000. Facing up to the meaning of "face up to": A cognitive semanticopragmatic analysis of an English verb-particle construction. In: Foolen, A. and F. Van der Leek (eds.), Constructions in Cognitive Linguistics. Selected papers from the fifth International Cognitive Linguistics Conference. Amsterdam/Philadelphia: John Benjamins. 81-102.

Jakobson, R. 1965. Quest for the Essence of Language. Selected Writings II. The Hague: Mouton. 345-359.

Joy, A., Sherry, J.F., and J. Deschenes. 2009. Conceptual Blending in Advertising. Journal of Business Research 62. 39-49.

Kardela, H. 2006. (Nie)podobieństwo w morfologii: amalgamaty kognitywne. In: Kardela, H., Muszyński, Z. and M. Rajewski. (eds.) Kognitywistyka 2. Podobieństwo. Lublin: UMCS. 195-210.

Kemmer, S. 2003. Schemas and Lexical Blends. In: Radden G. and H. Cuyckens, H. (eds.), Motivation in Language: Studies in Honor of Günter Radden. Amsterdam/Philadelphia: John Benjamins. 69-95.

Kövecses, Z. 2002. Metaphor. A Practical Introduction. Oxford: OUP.

Lakoff, G. and M. Johnson 1980. Metaphors We Live By. Chicago: UCP.

Langacker, R. 1987. Foundations of Cognitive Grammar (vol. 1). Theoretical Prerequisites. Stanford: Stanford University Press. 
Langacker, R. 1991. Foundations of Cognitive Grammar (vol. 2). Descriptive Application. Stanford: Stanford University Press.

Langacker, R. 2000. A dynamic usage-based model. In: Barlow, M. and S. Kemmer (eds.), Usage-Based Models of Language. Stanford: CSLI Publications. 1-64.

Langacker, R. 2008. Cognitive Grammar: A Basic Introduction. Oxford: OUP.

Libura, A. 2007. Amalgamaty kognitywne w sztuce. Kraków: Universitas

Libura, A. 2010. Teoria przestrzeni mentalnych i integracji pojęciowej: struktura modelu $i$ jego funkcjonalność. Wrocław: Wydawnictwo Uniwersytetu Wrocławskiego.

Oakley, T. \& Coulson, S. 2008. Connecting the dots: Mental spaces and metaphoric language in discourse. In: Oakley, T. and A. Hougaard (eds.), Mental Spaces in Discourse and Interaction. Amsterdam/ Philadelphia: John Benjamins.27-50.

Oakley, T. and A. Hougaard. 2008. Mental Spaces in Discourse and Interaction. Amsterdam/Philadelphia: John Benjamins.

Omazić, M. 2005. Cognitive Linguistic Theories in Phraseology. Jezikoslovlje 6.1-2. $37-56$.

Plag, I. 2003. Word- Formation in English. Cambridge: CUP.

Rejakowa, B. 2008. Kulturowe aspekty języka mody. Lublin: UMCS.

Riemer, N. 2005. The semantics of polysemy. Reading meaning in English and Walrpiri. Cognitive Linguistics Research 30. Berlin, New York: Mouton de Gruyter.

Ryder, M. E. 1994. Ordered Chaos. The Interpretation of English Noun-noun Compounds. Berkeley: University of California Press.

Stępniak, K. 1993. Słownik tajemnych gwar przestępczych. Londyn: Wydawnictwo Puls.

Sweetser, E. 1999. Compositionality and Blending: semantic composition in a cognitively realistic framework. In: Janssen, T. and G. Redeker (eds.), Cognitive Linguistics: Foundations, Scope and Methodology. Berlin: Mouton de Gruyter. 129-162.

Turner, M. 1993. Reading Minds. The Study of English in the Age of Cognitive Science. Princeton University Press.

Turner, M. 1998. The Literary Mind. The Origins of Though and Language. Oxford University Press.

Ungerer, F. and H.J. Schmid. 2006 (1996). An Introduction to Cognitive Linguistics. Edinburgh: Pearson Education Ltd.

Veale, T. and D. O”Donoghue. 2000. Computation and Blending. In: Cognitive Linguistics II, 3/4. 253-281. 